\title{
Oil prices, tourism income and economic growth: A Structural VAR Approach for European Mediterranean countries
}

\author{
Ioannis Chatziantoniou ${ }^{1}$, George Filis $^{2}{ }^{2}$, Bruno Eeckels ${ }^{3}$, Alexandros Apostolakis ${ }^{4}$ \\ Affiliations \\ 1, 4University of Portsmouth \\ Department of Economics and Finance \\ Richmond Building, Portland Street, PO1 3DE \\ Portsmouth, UK \\ ${ }^{2}$ Bournemouth University \\ Department of Accounting, Finance and Economics \\ The Executive Business Centre, \\ 89 Holdenhurst Road, BH8 8EB \\ Bournemouth, UK \\ ${ }^{3}$ Les Roches-Gruyère, \\ University of Applied Sciences, \\ Bluche, 1815, Switzerland \\ *Corresponding author: gfilis@bournemouth.ac.uk, tel:+44 1202 968739, \\ fax:+44 1202968833
}

\begin{abstract}
In this study, a Structural VAR model is employed to investigate the relationship among oil price shocks, tourism variables and economic indicators in four European Mediterranean countries. In contrast with the current tourism literature, we distinguish between three oil price shocks, namely, supply-side, aggregate demand and oil specific demand shocks. Overall, our results indicate that oil specific demand shocks contemporaneously affect inflation and the tourism sector equity index, whereas these shocks do not seem to have any lagged effects. By contrast, aggregate demand oil price shocks exercise a lagged effect, either directly or indirectly, to tourism generated income and economic growth. The paper does not provide any evidence that supply-side shocks trigger any responses from the remaining variables. Results are important for tourism agents and policy makers, should they need to create hedging strategies against future oil price movements or plan for economic policy developments.
\end{abstract}

JEL: C32, F43, L83, O14, O52

Keywords: Oil price shocks, tourism income, economic growth, SVAR, European countries 


\section{Introduction and review of the literature}

Recent hikes in oil prices have necessitated the investigation of the relationship among tourism sector developments, economic growth and oil price movements. This investigation is considered very topical for the tourism industry given its energy-intensive nature (Becken, 2008; Gössling et al., 2005; Patterson and McDonald, 2004). Oil price changes could harm economic and tourism activities due to the effect they exert on transportation, production costs, economic uncertainty and disposable income (Becken, 2008). Especially for tourism dependent countries, income derived from the tourism sector could potentially help them facilitate future development strategies and goals or help them forge a resilient economy. In this regard, it is understood that tourism may very well serve as the engine for boosting aggregate demand and thus leading to economic growth.

In the light of recent developments in economic conditions in Europe that consequently brought the matters of 'short-run stability' and 'medium-run economic growth' to the fore, identifying potential sources of growth constitutes a great challenge for any European country, but especially for the EMU periphery. The latter countries need to focus on the aggregate demand side of their economy in order to find ways to increase consumption and tourism sector could constitute an important driver of economic growth, since it represents an important component of their economy. Nevertheless, emphasis should be put upon the fact that countries with a high dependency on tourism activity are unevenly exposed to sudden fluctuations in oil prices (Becken and Lennox, 2012). This entails careful planning as potential benefits of the tourism sector's developments could be diminished by higher oil prices.

In this regard, the purpose of the following analysis is two-fold. Initially, we review the literature associated with the relationship between economic growth and the tourism industry. Next, we highlight past findings related to the effects of oil prices on the economy.

\subsection{Tourism and economic growth}

Building on the seminal theoretical work of Hazari and Sgrò (1995), Lanza and Pigliaru (1999), as well as, Copeland (1991), many authors have conducted research in order to provide empirical findings regarding the interaction between the tourism sector and the broader economy. Nevertheless, the causality between the tourism sector and economic 
growth is a matter yet open to question. To be more explicit, research on the field can empirically support four main views on the said relationship:

- First, there is evidence that causality indeed runs from the tourism-sector to the broader economy - a hypothesis known as the tourism led economic growth (TLEG) hypothesis (see, inter alia, Fayissa et al., 2011; Schubert, 2011; Brida et al., 2010; Zortuk, 2009; Lee and Chang, 2008; Croes and Vanegas, 2008; Carrera et al., 2008; Soukiazis and Proenca, 2008; Kim et al., 2006; Vanegas and Croes, 2003; Blake and Sinclair, 2003; Balaguer and Catavella-Jorda, 2002).

- Then, there is the view that economic growth is instead a crucial factor to the increase in tourism income - the so called economic-driven tourism growth (EDTG) hypothesis (Oh, 2005; Narayan, 2004)

- A third strand of literature provides evidence that there exists bidirectional causality between tourism and economic growth (Kassimati, 2011; Chen and Chiou-Wei, 2009; Cortes-Jimenez et al., 2009; Lee and Chang, 2008; Dritsakis, 2004; Drubary, 2004, among others).

- Finally there are some authors reporting no significant evidence for causality (Katricioglou, 2009; Eugenio-Martin and Morales, 2004).

In particular, the overriding assumption underpinning the TLEG hypothesis is that rising tourism income has multiple advantages for a country's economy, including inter alia, rising employment in the tourism sector, development of other business sectors related to tourism activities and a positive effect on the national balance of payments due to higher tourism receipts.

Pertaining to the view that economic growth leads to tourism growth, the argument is that any policy initiatives that promote overall economic development should take precedence over measures that directly promote tourism growth. Under this view, this growth will result in the expansion of the tourism sector.

Nevertheless, as aforementioned, other findings do not provide support either in favour of the TLEG or the EDTG, whereas some studies opine in favour of bidirectional causality between tourism income and economic growth. Table 1 summarises previously reported empirical results.

[TABLE 1 HERE] 


\subsection{The effects of oil prices}

Nevertheless, all aforementioned findings could be significantly influenced by oil price fluctuations. Previous research has indicated that higher oil prices exert a negative impact on tourism (Becken and Lennox, 2012; Becken, 2011; Yeoman et al., 2007). In testament to that, the current global economic turbulence and political events in the Middle East have created uncertainty in commodity markets and oil prices are expected to peak in the following years. The United Nations World Tourism Organisation (UNWTO) has also expressed its concern regarding the negative effects of oil prices on tourism (WTO, 2006). In addition, the UNWTO has concluded that high oil prices are affecting certain tourism industry segments (e.g. airlines, cruise lines, etc.) disproportionately more than others.

Furthermore, Becken (2011) distinguishes between macroeconomic and microeconomic effects of oil prices. For oil-importing countries (such as the countries in our sample) this translates as follows. With reference to macroeconomic effects, higher oil prices generally lead to higher inflation, while they negatively influence the country's income. From a microeconomic perspective, positive oil price shocks lead to a decline in disposable income. These developments will have an immediate and negative impact on tourism, mainly due to the fact that tourism is regarded as a luxury good (Lim et al., 2008; Nicolau, 2008; Dritsakis, 2004).

The oil-literature further distinguishes oil price innovations in virtue of their origin. Indicatively, we quote Hamilton $(2009 a, b)$ who draws a distinctive line between demandside oil price shocks (due to the industrialization of countries such as China) and supply-side shocks (due to interruptions in the supply of oil). Kilian (2009), in addition to Hamilton's origins of oil price shocks, further identifies the so-called precautionary oil price shock or oil specific demand shock (this is a shock associated with the uncertainty about the future availability of price of oil).

The consideration of the origin of oil price shocks is rather important as the literature has shown that different shocks impose different effects on economic variables and thus they may possibly yield different effects on the tourism sector (authors who have considered the origin of the oil price shock in their studies include Kilian and Lewis (2011), Filis et al. (2011), Apergis and Miller (2009), Lescaroux and Mignon (2008), Kilian (2008) and Barsky and Kilian (2004)). In short, the consensus is that supply-side shocks, in general, exert either insignificant or negative impacts, whereas demand-side shocks appear to have both short- 
run and long-run positive effects (Baumeister and Peersman, 2012; Hamilton, 2009a,b; Lippi and Nobili, 2009). This established, Kilian and Park (2009) suggest that only aggregate demand side shocks exert a positive effect, whereas oil specific demand shocks trigger negative responses from economic variables.

Given this vast pool of different approaches and findings, the effects of oil price shocks on countries that heavily rely on tourism have been under-researched (Becken, 2011). In addition, as tourism is an oil-intensive industry, the literature has remained particularly silent on this relationship. For this reason, Becken (2011) urges for more research in this specific area.

\subsection{Purpose of study}

Having established that the interaction between tourism income and economic growth should also encompass the effects of oil prices shocks, this paper examines the relationship between oil price shocks, tourism income and economic growth, taking under consideration the origin of the oil price shocks (i.e. whether it is a supply-side oil price shock, an aggregate demand-side oil price shock or an oil specific demand shock).

For this study we consider data from four European economies, namely, France, Italy, Spain and Greece. The choice of the countries was influenced by the fact that their tourism sector has a significant contribution to their economy. In addition, Italy, Spain and Greece are the three main countries that face significant debt problems, while France was chosen as it is the main core European country that has been hit by the debt crisis, so far.

The results reveal that the origin of the oil price shocks is important in order to understand the effects of oil on tourism and the economy. More specifically, demand-side oil price shocks have a significant impact on tourism and economic variables, whereas this does not hold for the supply-side shocks. In particular, oil specific demand shocks exercise a contemporaneous effect on inflation (positive) and the tourism sector equity index (negative). On the other hand aggregate demand oil price shocks tend to favour, either directly or indirectly, the economic and tourism activity. The latter also affect the relationship between tourism and economic growth.

These results are of particular importance as they could facilitate tourism agents and policy makers, should they need to hedge against oil price movements and plan for economic development, respectively. 
The rest of the paper is structured as follows. Section 2 provides an overview of the tourism sector for the countries under investigation. The methodology and data used are presented in Section 3. Subsequently, empirical results are analysed in Section 4, whereas Section 5 considers policy implications related to empirical findings, before a conclusion is reached in Section 6.

\section{Overview of the tourism sectors in the countries under investigation}

As a starting point for the discussion to follow, Table 2 summarises basic industry measurements and indicators from the four countries under consideration during the period of 2000-2010. The purpose of this section is to verify the significance of inbound tourism for the countries under examination.

\section{[TABLE 2 HERE]}

In absolute terms, France is the recipient of the majority of inbound tourists, followed by Spain, Italy, and then Greece. Domestic tourism, as this is measured in terms of overnight stays, presents a similar picture, only with Italy being second and Spain third. The majority of tourists arriving in Italy, Spain and Greece are overnight visitors (62\%, 60\%, and over $90 \%$ respectively). Evidently, all countries in the sample exhibit a peak on inbound overnight visitors in 2007 (Figure 2). This is followed by a downward trend that can be possibly attributed to the aftermath of the 2008 credit crunch.

In terms of macro-economic indicators, Spain and Greece exhibit a higher contribution of inbound tourism expenditure to GDP ( $4.8 \%$ to $5.6 \%$ on average, respectively) compared to that of Italy and France (1.6\% and $2.1 \%$, respectively). In addition, the ratio of tourism expenditure to export of services averages to about $40 \%-50 \%$.

The mode of transport is an important element of the tourism product. Table 3 shows the two preferred modes used by inbound tourists over the 2000-2010 period.

[TABLE 3 HERE]

Tourists arriving in France and Italy travelled mainly by land ( $68 \%$ and $70.4 \%$ on average respectively). On the other hand, tourists in Spain and Greece arrived mainly by air $(74.2 \%$ and $71.5 \%$ on average respectively). This pattern can be explained by the particular geographical locations of the respective countries, as well as, the different tourism typologies they serve. 
Based on the aforementioned statistics we can deduce that the tourism sector is an integral and important part of all economies under investigation. In addition, due to the oil-intensive character of the tourism industry, we can further deduce that higher oil prices could have a negative impact on the four countries' economic prospects. This impact is further aggravated given that inbound tourism, which depends on oil-consuming transportation means, is the main type of tourism in all countries.

\section{Methodology and Data Description}

\subsection{Data Description}

We use monthly data from 2000:1 until 2010:12 from four countries, namely France, Italy, Spain and Greece. The variables under consideration are the world oil production levels, global economic activity index, crude oil prices, CPI, tourism sector equity index, tourism income and industrial production index. The global economic activity index is based on the dry cargo freight rates and it is constructed by Lutz Kilian (see, Kilian, 2009). All prices are real, seasonally adjusted and are expressed in growth rates. Data have been extracted from Datastream .

The paper will make use of world oil production levels, the global economic activity index and oil prices to identify the three oil price shocks, in the same spirit with Kilian and Park (2009). Section 3.2 provides a detailed explanation of the identification scheme for the model.

Furthermore, the tourism sector equity index tracks the stock price movements of the tourism sector firms, which are listed in the stock markets of the countries under investigation. The choice of tourism sector equity index is motivated by the fact that financial markets tend to react immediately to new information, which in our case could be news related to oil price changes. Thus, the potential effects of oil prices on the tourism industry could be identified through the behaviour of stocks that are listed in the tourism sector equity index.

The tourism income series represents income that is generated by inbound tourists. The choice of tourism income from inbound tourists is justified by the fact that spending from inbound tourists has a significant contribution to the economies under investigation, as evidenced in section 2 . 
Finally, economic growth is approximated by the growth rate of the industrial production index. The relevant literature in the economics area has, rather overwhelmingly, embraced the use of the industrial production index as a proxy for economic growth (Espinoza, Fornari and Lombardi, 2012; Lombardi and Van Robays, 2011; Peersman and Van Robays, 2011; Bjornland and Leitmeno, 2009; Laopodis, 2009, 2006; Kim and Roubini, 2000, among others). Thus, the inference of the results is not that tourism income could influence the industrial production per se but rather that the tourism income could influence the economic growth, as this is approximated by the industrial production.

Figure 1 summarizes the abovementioned series.

\section{[FIGURE 1 HERE]}

Figure 1 shows the effect of the 2008 financial crisis, as all industrial production indices, tourism stock market equity indices, oil prices, as well as, global economic activity exhibit a significant drop during this period. Furthermore, the tourism income for all countries in the sample shows a decreasing pattern since 2008 , with some evidence of recovery during the last period of our study.

\subsection{Structural VAR framework}

We examine the dynamic relationship among oil price shocks, tourism income and economic growth, using the SVAR framework. In particular, we consider the following variables in our model: oil production, global economic activity, oil prices, CPI, tourism sector equity index returns, tourism income and industrial production index.

The structural representation of the VAR model of order $p$ takes the following general form:

$$
\mathbf{A}_{0} \mathbf{y}_{t}=\mathbf{c}_{0}+\sum_{i=1}^{p} \mathbf{A}_{i} \mathbf{y}_{t-i}+\boldsymbol{\varepsilon}_{t}
$$

where, $\mathbf{y}_{t}$ is a $7 \times 1$ vector of endogenous variables, i.e. $\mathbf{y}_{t}=\left[\right.$ oil $_{t}$, gea $_{t}$, oilp $\left._{t}, \pi_{t}, \mathrm{sm}_{t}, \mathrm{t} i_{t}, y_{t}\right]$, $\mathbf{A}_{0}$ represents the $7 \times 7$ contemporaneous matrix, $\mathbf{A}_{i}$ are $7 \times 7$ autoregressive coefficient matrices, $\varepsilon_{t}$ is a $7 \times 1$ vector of structural disturbances, assumed to have zero covariance and be serially uncorrelated. The covariance matrix of the structural disturbances takes the 
following form $E\left[\boldsymbol{\varepsilon}_{t} \boldsymbol{\varepsilon}_{t}^{\prime}\right]=\mathbf{D}=\left[\begin{array}{lllllll}\sigma_{1}^{2} & \sigma_{2}^{2} & \sigma_{3}^{2} & \sigma_{4}^{2} & \sigma_{5}^{2} & \sigma_{6}^{2} & \sigma_{7}^{2}\end{array}\right] \times \mathbf{I}$. In order to get the reduce form of our structural model (1) we multiply both sides with $\mathbf{A}_{0}^{-1}$, such as that:

$$
\mathbf{y}_{t}=\mathbf{a}_{0}+\sum_{i=1}^{p} \mathbf{B}_{i} \mathbf{y}_{t-i}+\mathbf{e}_{t}
$$

where, $\mathbf{a}_{0}=\mathbf{A}_{0}^{-1} \mathbf{c}_{0}, \mathbf{B}_{i}=\mathbf{A}_{0}^{-1} \mathbf{A}_{i}$, and $\mathbf{e}_{t}=\mathbf{A}_{0}^{-1} \boldsymbol{\varepsilon}_{t}$, i.e. $\boldsymbol{\varepsilon}_{t}=\mathbf{A}_{0} \mathbf{e}_{t}$. The reduced form errors $\mathbf{e}_{t}$ are linear combinations of the structural errors $\varepsilon_{t}$, with a covariance matrix of the form $E\left[\mathbf{e}_{t} \mathbf{e}_{t}^{\prime}\right]=\mathbf{A}_{0}^{-1} \mathbf{D} \mathbf{A}_{0}^{-1^{\prime}}$.

The structural disturbances can be derived by imposing suitable restrictions on $\mathbf{A}_{0}$. The short-run restrictions that are applied in this model as the following:

$$
\left[\begin{array}{c}
\varepsilon_{1, t}^{s s} \\
\varepsilon_{2, t}^{a d s} \\
\varepsilon_{3, t}^{s d s} \\
\varepsilon_{4, t}^{p s} \\
\varepsilon_{5, t}^{s m s} \\
\varepsilon_{6, t}^{t s} \\
\varepsilon_{7, t}^{i s}
\end{array}\right]=\left[\begin{array}{ccccccc}
a_{11} & 0 & 0 & 0 & 0 & 0 & 0 \\
a_{21} & a_{22} & 0 & 0 & 0 & 0 & 0 \\
a_{31} & a_{32} & a_{33} & 0 & 0 & 0 & 0 \\
a_{41} & a_{42} & a_{43} & a_{44} & 0 & 0 & 0 \\
a_{51} & a_{52} & a_{53} & a_{54} & a_{55} & a_{56} & a_{57} \\
a_{61} & a_{62} & a_{63} & a_{64} & 0 & a_{66} & 0 \\
a_{71} & a_{72} & a_{73} & 0 & 0 & a_{76} & a_{77}
\end{array}\right] \times\left[\begin{array}{c}
e_{1, t}^{\text {oils }} \\
e_{2, t}^{g e a} \\
e_{3, t}^{\text {oilp }} \\
e_{4, t}^{\pi} \\
e_{5, t}^{s m t} \\
e_{6, t}^{t i} \\
e_{7, t}^{y}
\end{array}\right]
$$

where, $s s=$ supply-side oil price shock, ads = aggregate demand oil price shock, $s d s=$ oil specific demand shock, ps = price shock, sms = stock market shock, ts = tourism income shock and is = income shock.

The restrictions in our model can be explained as follows. Following Kilian and Park (2009), the first three equations are used for the identification of the oil price shocks. More specifically, oil production is not responding contemporaneously to changes in oil demand due to the high adjustment costs. On the contrary, oil supply changes can contemporaneously influence global economic activity and the price of oil. Furthermore, the global economic activity is not contemporaneously influenced by oil prices, as it requires time for the world economy to react to oil price changes. Nevertheless, changes in the aggregate economic activity will have an immediate impact on oil prices due to the immediate reaction of the commodities markets. Finally, the oil price innovation could be triggered by supply-side events, aggregate demand-side events, as well as, oil specific demand events. Thus, oil production shocks, as well as, aggregate demand shocks can contemporaneously impact oil prices. 
Turning to the responses of the remaining variables in our model, we argue that all three oil price shocks are imposing inflationary pressures in the economy. As a result, inflation is contemporaneously influenced by these shocks, but not influenced contemporaneously by any other variables. Next, the tourism sector equity index responds immediately to all shocks by all variables. In addition, both tourism income and industrial production do not receive a contemporaneous effect from the tourism sector index. This model is also designed to capture any contemporaneous effect running from the tourism income to economic growth.

We expect that inbound tourism income can contemporaneously assist the economic growth (as this is approximated by the industrial production) of a country. On the contrary, we do not expect that the economic growth could exert a contemporaneous impact on inbound tourism income. We argue that the greater the economic growth, the stronger the economy is and thus, there are more opportunities to create a stable economic environment with better infrastructure in an effort to attract more inbound tourists. Nevertheless, these effects cannot be observed contemporaneously. Finally, industrial production is not affected contemporaneously by inflation due to the reaction time that is required between changes in price levels and changes in demand.

To proceed to the estimation of the reduced form of model (2), it is first necessary to establish the stationarity of the variables. The ADF and PP unit root tests suggest that all variables are I(0). The order of the VAR model was identified using the Akaike Information Criterion (AIC). The AIC suggested a VAR model of order two ${ }^{1}$. The model does not suffer from autocorrelation or heteroskedasticity, as suggested by the serial autocorrelation LM test, portmanteau joint test and White heteroscedascitity test ${ }^{2}$.

\section{Empirical Findings}

\subsection{Contemporaneous relationships}

Table 4 summarises the contemporaneous coefficients for the countries under investigation. It is evident that only the oil specific demand shock is exercising contemporaneous effects on the economic and tourism variables. More specifically, oil specific demand shocks exert a negative effect on tourism sector equity indices (coefficients $\alpha_{53}$ are negative and significant)

\footnotetext{
${ }^{1}$ Results are available upon request.

${ }^{2}$ Results are available upon request.
} 
and a positive effect on inflation (coefficients $\alpha_{43}$ are positive and significant), on all countries in our sample. This is an anticipated result considering that all countries are oilimporters. Furthermore, the oil specific demand shock has a negative and contemporaneous effect on tourism income in Italy (see coefficient $\alpha_{63}$ ). From this, we deduce that expectations regarding the future availability of oil that trigger oil specific demand shocks are very important in contemporaneous terms. In particular, expectations revolving around oil shortages in the future may lead to market turbulence and thus a reduction in tourism indicators is observed.

The fact that the economic and tourism indicators are not affected contemporaneously by supply-side shocks (coefficients $\alpha_{41}, \alpha_{51}, \alpha_{61}$ and $\alpha_{71}$ are not significant) and aggregate demand side shocks (coefficients $\alpha_{42}, \alpha_{52}, \alpha_{62}$ and $\alpha_{72}$ are not significant) suggests a delayed response due to the time that is required for these indicators to reflect changes in oil prices.

[TABLE 4 HERE]

It is worth noting that although the contemporaneous effects of tourism income on the tourism sector equity index are positive (see coefficient $\alpha_{56}$ ); they are not significant. A plausible explanation of this finding is that tourism income effects to the stock market may not be direct but may instead be filtered through other channels, such as the performance of the listed tourism firms, the performance of the overall stock market, etc. Nevertheless, our model is not designed to capture all these different channels, as they fall outside the research remit of this paper.

In terms of the effects of economic growth on the tourism sector equity index the results suggest that these are positive and significant for Italy and Spain (see coefficient $\alpha_{57}$ ) only.

Overall, these findings signify the importance of the origin of the oil price shock, as not all of them affect the economic and tourism variables. Next we turn our focus on the analysis of the impulse response functions.

\subsection{Accumulated Lagged Responses (Impulse responses)}

\subsubsection{France}

The results in Figure 2a suggest that supply-side oil price shocks do not exert any effect on any economic or tourism variables. On the other hand, the empirical results indicate a significant impact of the demand-side shocks on inflation (negative) and industrial production (positive). 


\section{[FIGURE 2a HERE]}

The aggregate demand oil price shock exercises a negative effect on inflation and a positive effect on industrial production, whereas the oil specific demand shock leads to an increase on inflation and decrease on industrial production. This finding is anticipated as aggregate demand oil price shocks suggest a boom in the global economy, which could influence the individual economies in a positive manner (i.e. lower inflation and higher production levels). The reverse holds for the oil specific demand shocks, which are considered as negative news and thus could result in inflationary pressures and lower production levels. We also find positive bidirectional causality between tourism income and industrial production. The only other determinant of industrial production, as evidenced from the impulse response functions, is the tourism sector equity index.

In addition, the tourism sector equity index exhibits a positive response from the industrial production, which is significant for a very short period of time. We do not report any response from the tourism sector equity index on a tourism income shock. The forgoing explanation regarding the contemporaneous effects of tourism income on tourism sector equity index provides a valid source of explanation for this case, as well.

In retrospect, we find evidence that oil price shocks are important determinants of the tourism income and the economy, either directly or indirectly. On the one hand, positive aggregate demand oil price shocks affect inflation favourably (i.e. they cause a reduction of inflation). On the other hand, positive aggregate demand oil price shocks lead to increased industrial production, which in turn, it has a positive effect on tourism income. The exact opposite causalities hold for the oil specific demand shocks. Interestingly enough we find no relationship between tourism income and the tourism sector equity index.

\subsubsection{Italy}

The reaction of the economic and tourism indicators to oil price shocks are displayed on Figure $2 \mathrm{~b}$. As evident by the impulse responses, inflation is reacting negatively to a positive aggregate demand oil price shock, whereas the tourism sector index, tourism income and industrial production are responding positively to the same shock. Similarly to the situation described in the French case, a positive oil specific demand shock exerts opposite effects on inflation (positive) and industrial production (negative). Furthermore, we do not find evidence that the tourism sector equity index, the tourism income and industrial production 
respond to any supply-side oil price shocks. In addition, the two tourism indicators do not respond to the oil specific demand shocks, as well. However, a positive tourism sector equity index shock is exercising a positive effect on industrial production, yet it fails to trigger a reaction from the tourism income. Similarly, tourism income and industrial production shocks do not generate any response from the equity index of the tourism sector, similarly to the case of France. Finally, the impulse responses suggest a positive unidirectional causality between tourism sector index and industrial production, running from the earlier to the latter.

\section{[FIGURE 2b HERE]}

Overall, we observe that aggregate demand oil price shocks have a positive impact on tourism and economic growth, whereas the opposite holds for the oil specific demand shock. Thus, considering that tourism has a positive impact on industrial production, we argue that demand-side oil price shocks exercise both direct and indirect effect (via the tourism income) on economic growth.

\subsubsection{Greece}

As far as Greece is concerned, a positive aggregate demand oil price shock has a positive effect on both tourism income and industrial production, as suggested by the impulse responses, although not significant, especially in the case of industrial production (see Figure 2c). In addition, inflation, tourism income and industrial production react positively to a positive tourism sector equity index shock. The reverse causality between inflation and the tourism sector equity index holds as well, with the effect of inflation on tourism sector index to be negative. Finally, industrial production influences tourism income in a positive way. The latter finding suggests that the EDTG hypothesis is valid for Greece, which is partially in contrast to the evidence provided by Kasimati (2011) and Dritsakis (2004). As with the case of France and Italy, the empirical results for Greece suggest that aggregate demand oil price shocks impact tourism income in a positive way.

[FIGURE 2C HERE]

\subsubsection{Spain}

The impulse responses for Spain (see Figure $2 \mathrm{~d}$ ) suggest that tourism income and industrial production are responding positively to a positive aggregate demand oil price shock. We do 
not report any effects of the supply-side and oil specific demand shocks on tourism income, tourism sector equity index and industrial production. Nevertheless, a positive oil specific demand shock causes inflationary pressures. Furthermore, the tourism sector equity index exercises a positive effect on industrial production and tourism income, whereas it does not respond to any oil price shocks. Practically, the above statement implies that the tourism sector equity index can be used as a leading indicator of both industrial production and tourism income. Thus, any positive or negative news related to the industrial production and tourism income will be immediately incorporated into the tourism sector equity index.

Finally, support to the EDTG hypothesis is provided by the impulse responses, as a positive industrial production shock triggers a positive response from the tourism income. The latter finding runs counter to Balaguer and Cantavella-Jorda (2002) suggestions, who found evidence of bidirectional causality. To summarise, the EDTG hypothesis holds in the case of Spain. In addition, tourism income receives positive effects from the aggregate demand oil price shock, as well as, the tourism sector equity index.

[FIGURE 2d HERE]

\section{Policy Implications}

The findings of this study lead to the following policy implications. First, given inbound tourism's significance for all countries in the study sample and its high transportation costs (e.g. air fares), any oil price increase could lead to a reduction on inbound tourism activity. Thus, policy makers need to formulate such strategies to counterbalance income losses deriving from lower inbound tourism, or find ways to alleviate the dependence of these countries on inbound tourism activity, or even to minimise the cost of inbound tourism. For example, appropriate marketing strategies are required to boost both domestic and inbound tourism from neighbour countries. This argument stands to reason as a shorter travel distance entails lower travel costs. In addition, alternative travel modes should be promoted (e.g. train or road travel, etc), especially in the case of Spain and Greece, with respect to neighbouring countries, although this inevitably requires the development of sufficient infrastructure.

Furthermore, we maintain that government agencies should collaborate with the national tourism organisations with the view to identify the profile of tourists and evaluate their behaviour. Having done so, planning should then focus on the types of tourists that exhibit a 
lower price elasticity of demand. As the tourism product becomes more expensive, due to the effects of the oil specific demand shocks on the tourism sector, national tourism organisations can 'protect' their tourism balance of payments by focusing on less price sensitive demand segments. Thus, the change in demand will be significantly lower and tourism income will not fall considerably. In this regard, emphasis should be put upon the product's mix in order for each country to identify its competitive advantage and develop appropriate promotion strategies. For example, countries can focus on specific types of tourists, i.e. they can attract more business-type visitors, or they can rejuvenate the tourism product by offering alternative typologies of products. Thus, places like the countries in our sample (and especially those countries that have greater tourism dependency) could divert their attention towards 'soft' tourist products, as opposed to 'hard' tourism offerings. This implies that these countries could move away from the traditional 3S (sun-sea-sand) tourism model in order to take advantage of the worldwide movement towards the promotion of local and authentic activities through the promotion, for example, of local festivals and fairs. In addition, the tourism product within each country should be insulated against undesirable oil price movements and should reduce its oil dependency. In this way, countries will be able to accomplish a twofold goal; that is, to promote domestic tourism and outweigh the increased travel costs faced by inbound tourists. In the short-run, this can be achieved by promoting knowledge with regards to hedging strategies against oil price increases, due to demand-side shocks, that could be adopted by the domestic tourism agents, especially by major domestic transportation firms and tourist resorts.

Given the recent trends in the hospitality sector towards the exploitation of scale economies resulting from their operations (emergence of an all - inclusive model), the hospitality sector could also engage into different hedging strategies in order to alleviate some the pressures arising from potentially higher oil prices. In the long-run, each country should invest into alternative energy sources and energy efficiency practices in the sector (for example the adoption of more energy efficient practices in the hospitality sector, such as water recycling practices). Such a feat requires a better understanding of the factors that influence the diffusion and adoption of energy efficient practices in the tourism sector. The latter accommodates concerns about the future availability of oil, which triggers oil specific demand shocks that have a significant effect on tourism and the economy, as suggested by the empirical part of this study. 


\section{Concluding Remarks}

This empirical study uses a structural VAR model to investigate the links among oil price shocks, tourism sector and economic growth in four European Mediterranean countries. Disentangling oil price shocks into three categories, as suggested by Hamilton (2009a,b) and Kilian (2009), and using monthly data for the period 2000:1 - 2010:12, we find evidence to suggest that demand-side oil price shocks appear to exert an impact on tourism and the economy, whereas supply-side oil price shocks do not. To be more explicit, with reference to demand-side shocks, we observe that aggregate demand shocks have a significantly positive influence on tourism income and the economy (either directly or indirectly); nevertheless, this effect is not contemporaneously but it comes with a lag. On the other hand, oil specific demand shocks exercise a significant negative impact on tourism sector equity returns and inflation. This effect is only contemporaneous, though. Turning to the supply-side shocks, the absence of impact on both tourism industry and economy can be explained by the fact that changes in oil production do not significantly affect oil prices, as suggested by Kilian and Park (2009).

Previous research has illustrated a negative effect of oil prices on the tourism sector (see, Becken and Lennox, 2012; Becken, 2011; Yeoman et al., 2007). Nonetheless, these past findings give an incomplete picture, as they do not consider the origin of oil price changes. Overall, this study signifies the importance of the origin of oil price shocks in this area of research. The empirical results provide evidence to suggest that different oil price shocks trigger different types of responses.

Future research should concentrate on the effects of oil price shocks on tourism and economic growth for oil-exporting countries. In addition, it is essential that further studies examine these relationships in a time-varying environment. Finally, further research needs to be undertaken with respect to the effect of oil price shocks on different tourism segments. 


\section{References}

Apergis, N., \& Miller, S.M. (2009). Do structural oil-market shocks affect stock prices? Energy Economics, 31, 569-575.

Baumeister, C., \& Peersman, G. (2012). Time-varying effects of oil supply shocks on the US economy. Bank of Canada Working Paper Series, WP2012-02.

Ballaguer, J., \& Cantavella-Jorda, M. (2002). Tourism as a long-run economic growth factor: the Spanish case. Applied Economics, 34, 877-884.

Barsky, R. B., \& Kilian, L. (2004). Oil and the Macroeconomy since the 1970s. Journal of Economic Perspectives, 18(4), 115-34.

Becken, S. (2008). Developing indicators for managing tourism in the face of peak oil. Tourism Management, 29, 695-705.

Becken, S. (2011). Oil, the global economy and tourism. Tourism Review, 66, 65 - 72.

Becken, S., \& Lennox, J. (2012). Implications of a long-term increase in oil prices for tourism. Tourism Management, 33, 133-142.

Bjornland, H.C., \& Leitemo, K. (2009). Identifying the interdependence between us monetary policy and the stock market. Journal of Monetary Economics, 56, 275-282.

Blake, A., \& Sinclair, M.T. (2003). Tourism crisis management US response to September 11. Annals of Tourism Research, 30, 813-832.

Brida, J.G., Lanzilotta, B., Lionetti, S., \& Risso, W.A. (2010). The tourism-led growth hypothesis for Uruguay. Tourism Economics, 16, 765-771.

Carrera, E.J.S., Risso, W.A., \& Brida, J.G. (2008). Tourism's Impact on Long-Run Mexican Economic Growth. Economics Bulletin, 23(21), 1-8.

Chen, C.F., \& Chiou-Wei, S.Z. (2009). Tourism expansion, tourism uncertainty and economic growth: New evidence from Taiwan and Korea. Tourism Management, 30, 812818.

Copeland, B.R. (1991). Tourism, Welfare, and De-industrialization in a Small Open Economy. Economica, 58, 515-29.

Cortes-Jimenez, I., Pulina, M., Prunera, C., \& Artis, M. (2009). Tourism and Exports as a means of Growth. Research Institute of Applied Economics 2009 Working Papers.

Croes, R., \& Vanegas, M. (2008). Cointegration and Causality between Tourism and Poverty Reduction. Journal of Travel Research, 47, 94-103. 
Dritsakis, N. (2004). Tourism as long-run economic growth factors: an empirical investigation for Greece using causality analysis. Tourism Economics, 10(3), 305-316.

Durbarry, R. (2004). Tourism and economic growth: the case of Mauritius. Tourism Economics, 10(4), 389-401.

Espinoza, R., Fornari F., \& Lombardi, M.J. (2012). The role of financial variables in predicting economic activity. Journal of Forecasting, 31, 15-46.

Eugenio-Martin, J., Morales, N., \& Scarpa, R. (2004). Tourism and Economic Growth in Latin American Countries: A Panel Data Approach. FEEM Working Paper No. 26, Trieste, Italy: Global Network of Environmental Economists.

Fayissa, B., Nsiah, C., \& Tadesse, B. (2011). Research note: Tourism and economic growth in Latin American countries - further empirical evidence. Tourism Economics, 17, 1365-1373.

Filis, G., Degiannakis, S., \& Floros, C. (2011). Dynamic correlation between stock market and oil prices: The case of oil-importing and oil-exporting countries. International Review of Financial Analysis, 20, 152-164.

Gössling, S., Peeters, P., Ceron, J-P., Dubois, G., Patterson T., \& Richardson, R.B. (2005). The eco-efficiency of tourism. Ecological Economics, 54, 417-434.

Hamilton, J.D. (2009a). Understanding crude oil prices. Energy Journal, 30, 179-206.

Hamilton, J.D. (2009b). Causes and consequences of the oil shock of 2007-08. Brookings Papers on Economic Activity, Spring 2009, 215-261.

Hazari, B., \& Sgro, P. (1995). Tourism and Growth in a Dynamic Model of Trade. Journal of International Trade and Economic Development, 4, 253-56.

Kassimati, E. (2011). Economic impact of tourism on Greece's economy: Cointegration and causality analysis. International Research Journal of Finance and Economics, 79, 79-85.

Katircioglu, S.T. (2009). Revisiting the tourism-led-growth hypothesis for Turkey using the bounds test and Johansen approach for cointegration. Tourism Management, 30, 17-20.

Kilian, L. (2008). Exogenous oil supply shocks: how big are they and how much do they matter for the US economy?. Review of Economics and Statistics, 90, 216-240.

Kilian, L. (2009). Not all oil price shocks are alike: Disentangling demand and supply shocks in the crude oil market. American Economic Review, 99, 1053-1069. 
Kilian, L., \& Park, C. (2009). The impact of oil price shocks on the U.S. stock market. International Economic Review, 50, 1267-1287.

Kilian, L. \& Lewis, L.T. (2011). Does the Fed Respond to Oil Price Shocks?. Economic Journal, 121, 1047-1072.

Kim, H.J., Chen, M-H., \& Jang, "Shawn" S.C. (2006). Tourism Expansion and Economic Development: The Case of Taiwan. Tourism Management, 27, 925-33.

Kim, S., \& Roubini, N. (2000). Exchange rate anomalies in the industrial countries: A solution with a structural VAR approach. Journal of Monetary Economics, 45, 561-586.

Lanza, A., \& Pigliaru, F. (1999). Why are tourism countries small and fast growing? Universita' degli Studi di Cagliari, Working Paper No: 356.

Laopodis, N.T. (2006). Dynamic interactions among the stock market, federal funds rate, inflation, and economic activity. Financial Review, 41, 513-545.

Laopodis, N.T. (2009). Are fundamentals still relevant for European Economies in the post-Euro period. Economic Modelling, 26, 835-850.

Lee, C.C., \& Chang, C.P. (2008). Tourism development and economic growth: a closer look at panels. Tourism Management, 29, 180-192.

Lescaroux, F., \& Mignon, V. (2008). On the influence of oil prices on economic activity and other macroeconomic and financial variables. Centre $d^{\prime}$ Etudes Prospectives et $d^{\prime}$ Information Internationales, No 2008-05.

Lim, C., Min, J.C.H., \& McAleer, M. (2008). Modelling income effects on long and short haul international travel from Japan. Tourism Management, 29, 1099-1109.

Lippi, F., \& Nobili, A. (2009). Oil and the macroeconomy: A quantitative structural analysis. Bank of Italy Working Paper Series, No. 704.

Lombardi, M.J., \& Van Robays, I. (2011). Do financial investors destabilise the oil price? European Central Bank, Working Paper 1346.

Narayan, P.K. (2004). Economic impact of tourism on Fiji's economy: empirical evidence from the computable general equilibrium model. Tourism Economics, 10, 419-433.

Nicolau, J.L. (2008). Characterizing tourist sensitivity to distance. Journal of Travel Research, 47, 43-52.

Oh, C.O. (2005). The contribution of tourism development to economic growth in the Korean Economy. Tourism Management, 26, 39-44. 
Patterson, M.G., \& McDonald, G. (204). How green and clean is New Zealand tourism? Lifecycle and future environmental impacts. Lincoln: Landcare Research.

Peersman, G., \& Van Robays, I. (2011). Cross-country differences in the effects of oil shocks. Energy Economics, doi:10.1016/j.eneco.2011.11.010

Schubert, S.F., \& Brida, J.G. (2011). Dynamic model of economic growth in a small tourism driven economy. Tourism Economics, 3, 149-168.

Soukiazis, E., \& Proenca, S. (2008). Tourism as an alternative source of regional growth in Portugal: A panel data analysis at NUTS II and III levels. Portuguese Economic Journal, 7, 43-61.

United Nation World Tourism Organisation. (2006). The impact of rising oil prices on international tourism. Special report - World Tourism Organisation report, 26, 26-36.

Vanegas, M., \& Croes, R. (2003). Growth, Development and Tourism in a Small Economy: Evidence from Aruba. International Journal of Tourism Research, 5, 315-30.

Yeoman, I., Lennon, J., Blake, A., Galt, M., Greenwood, C., \& McMathon-Beattie, U. (2007). Oil depletion: What does this mean for Scottish tourism? Tourism Management, 28, 1354-1365.

Zortuk, M. (2009). Economic Impact of Tourism on Turkey's Economy: Evidence from Cointegration Tests. International Research Journal of Finance and Economics, 25, 231-239. 
Figures

Figure 1: Macroeconomic and financial series employed in the SVAR model (in logs)

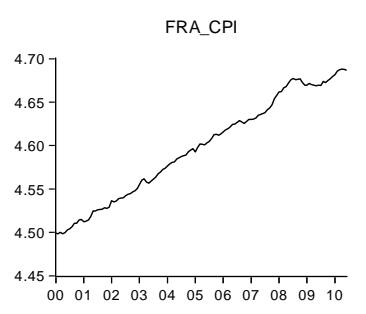

GR_CPI

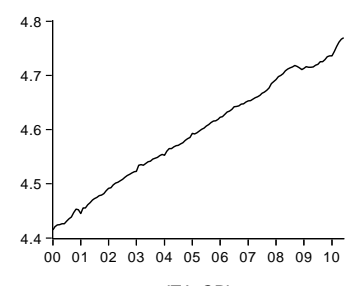

ITA CPI

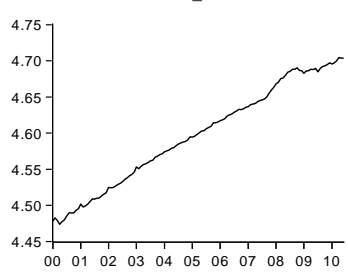

SPA_CPI

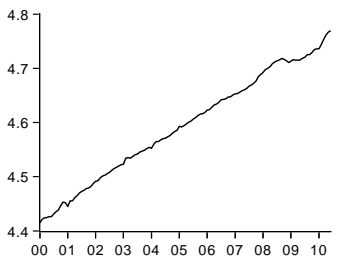

OIL_PRICE

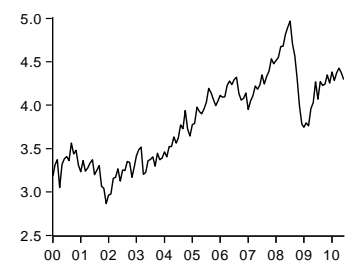

FRA_IP

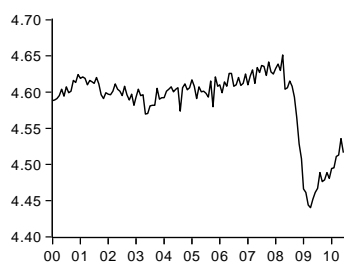

GR_IP

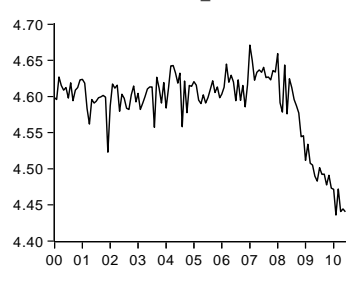

ITA_IP

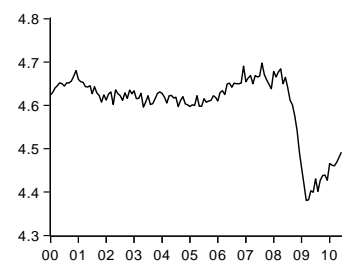

SPA_IP

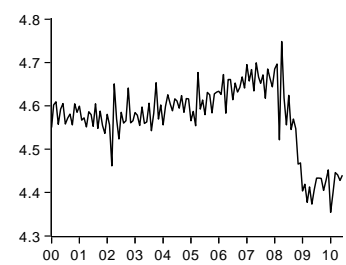

OIL_PRODUCTION

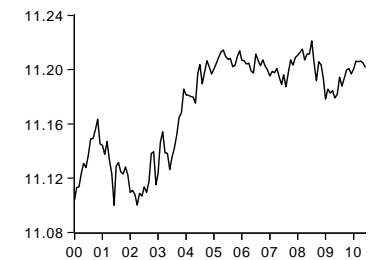

FRA_SMT

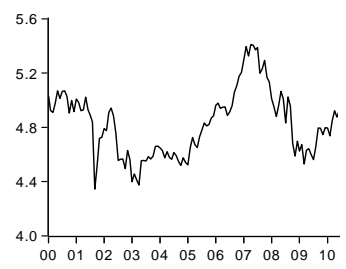

GR_SMT

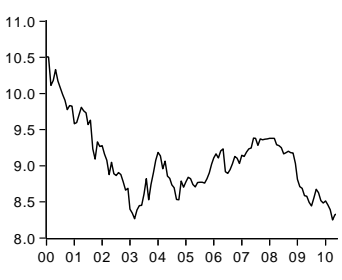

ITA_SMT

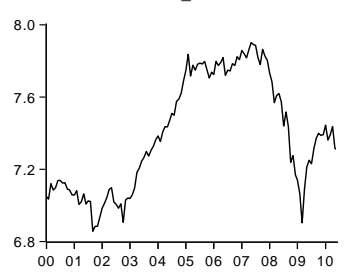

SPA_SMT

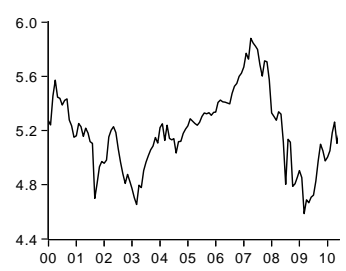

GEA

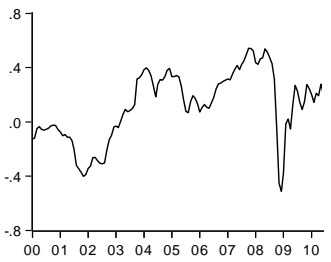

FRA_TI

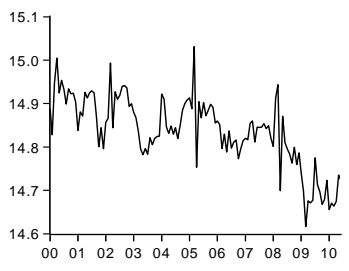

GR_TI

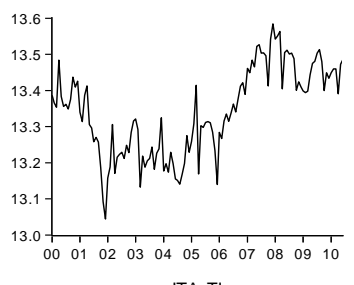

ITA TI

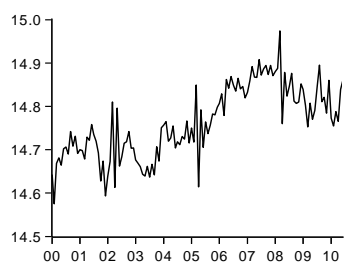

SPA_TI

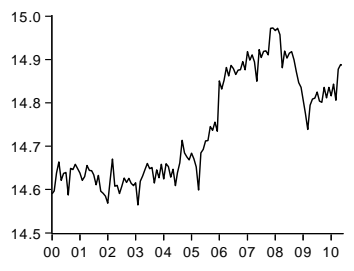

$\mathrm{CPI}=$ consumer price index, IP=industrial production, $\mathrm{SMT}=$ tourism stock market index, $\mathrm{TI}=$ tourism income, $\mathrm{GEA}=$ global economic activity 
Figure 2: Accumulated Impulse Responses

The lines represent the accumulated impulse responses of the inflation $\left(R_{-} C P I\right)$, tourism sector equity index $\left(R_{-} S M T\right)$, tourism income $\left(R \_T I\right)$ and industrial production (R_IP) to a positive supply-side oil price shock (shock 1), aggregate demand oil price shock (shock 2), oil specific demand shock (shock 3), price shock (shock 4), stock market shock (shock 5), tourism income shock (shock 6) and income shock (shock 7), respectively.

\section{2a. France}

Accumulated Response to Structural One S.D. Innovations \pm 2 S.E.

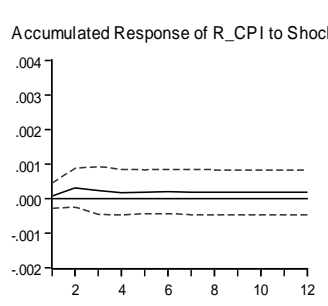

Accus

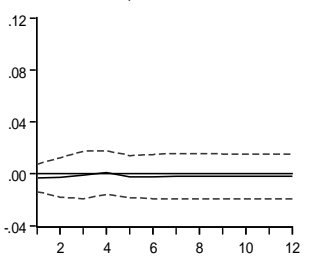

Accumulated Response of R

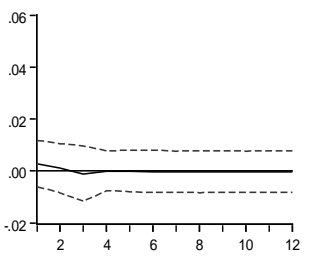

Accumulated Response of R.IP to Shock
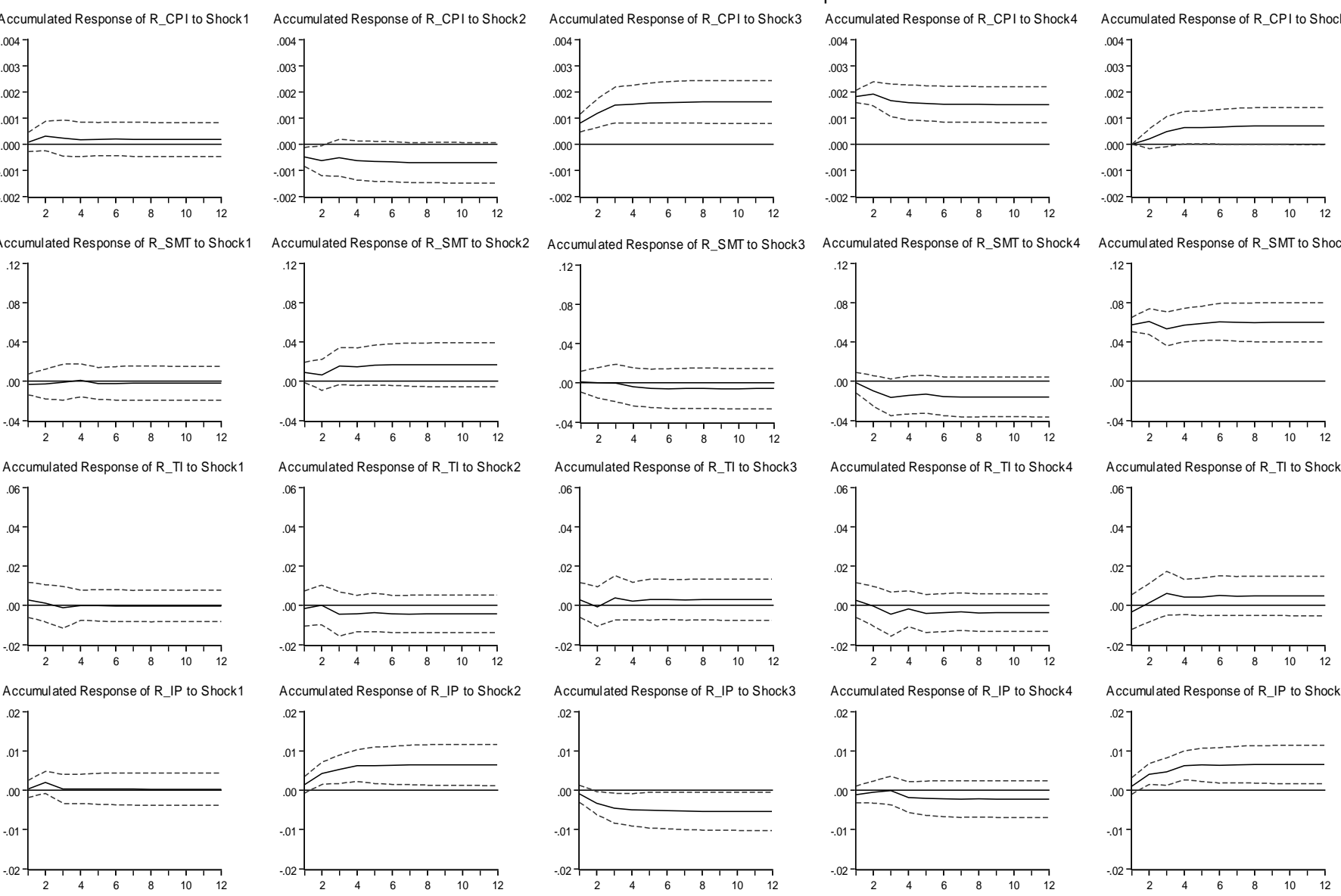

Accumulated Response of $R_{-}$TI to Shock2
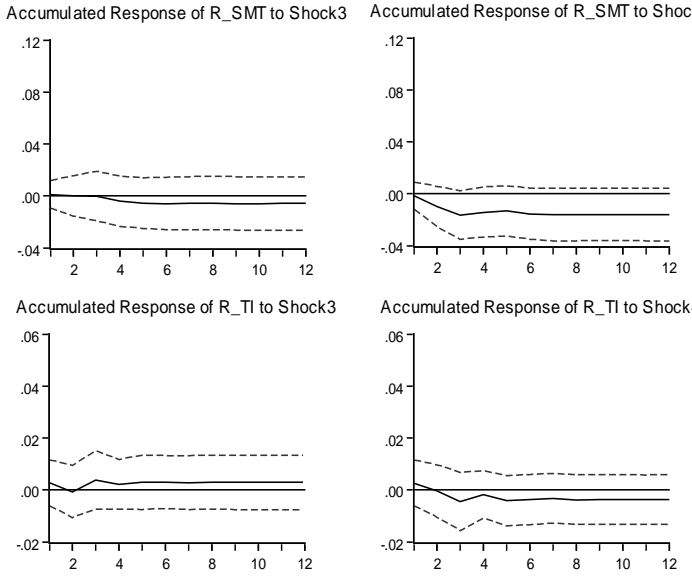

Accumulated Response of $\mathrm{R} \_\mathrm{T}$ t to Shock

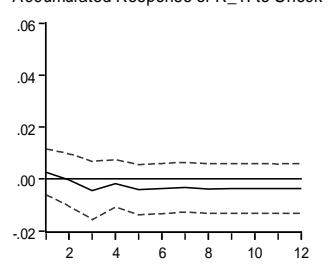

Accumulated Response of R_IP to Shock3
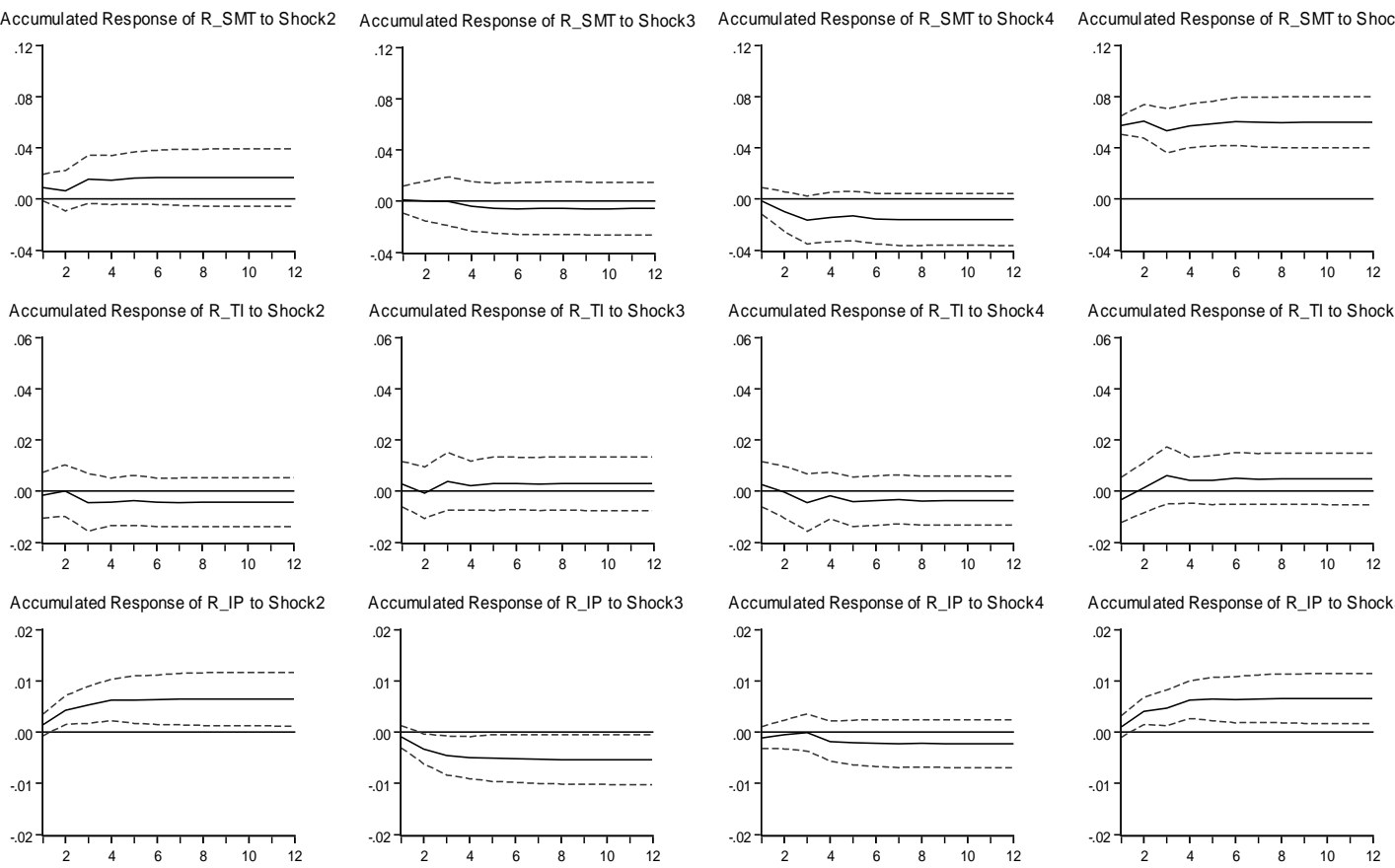

Accumulated Response of R_ _t t to Shock5
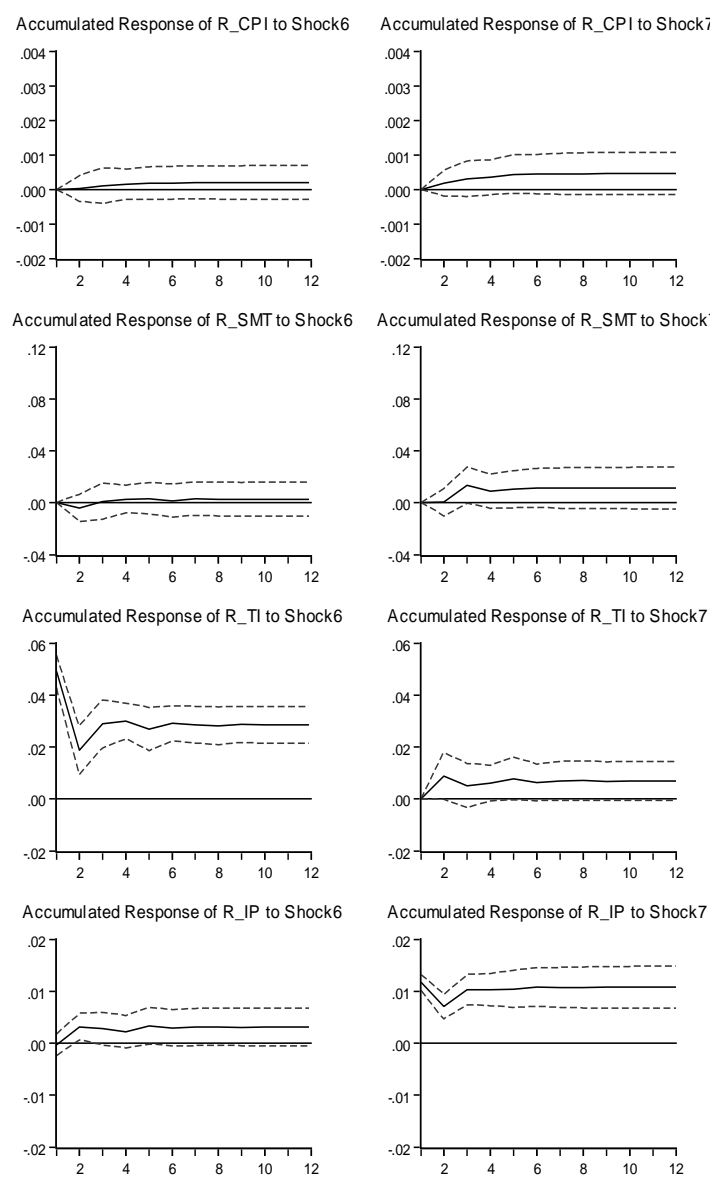
Accumulated Response to Structural One S.D. Innovations \pm 2 S.E.

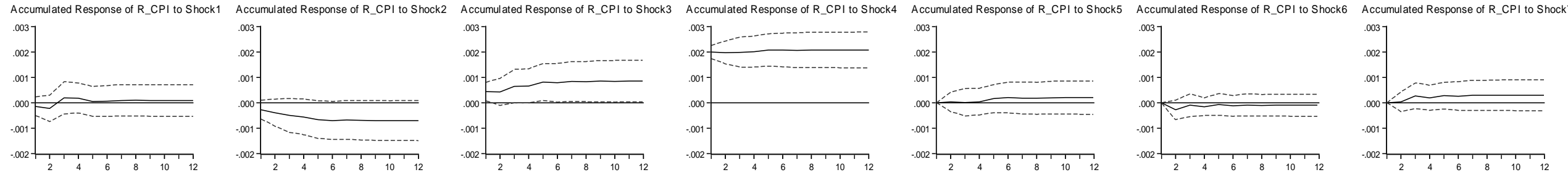

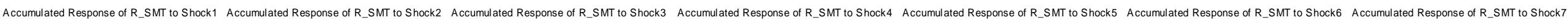
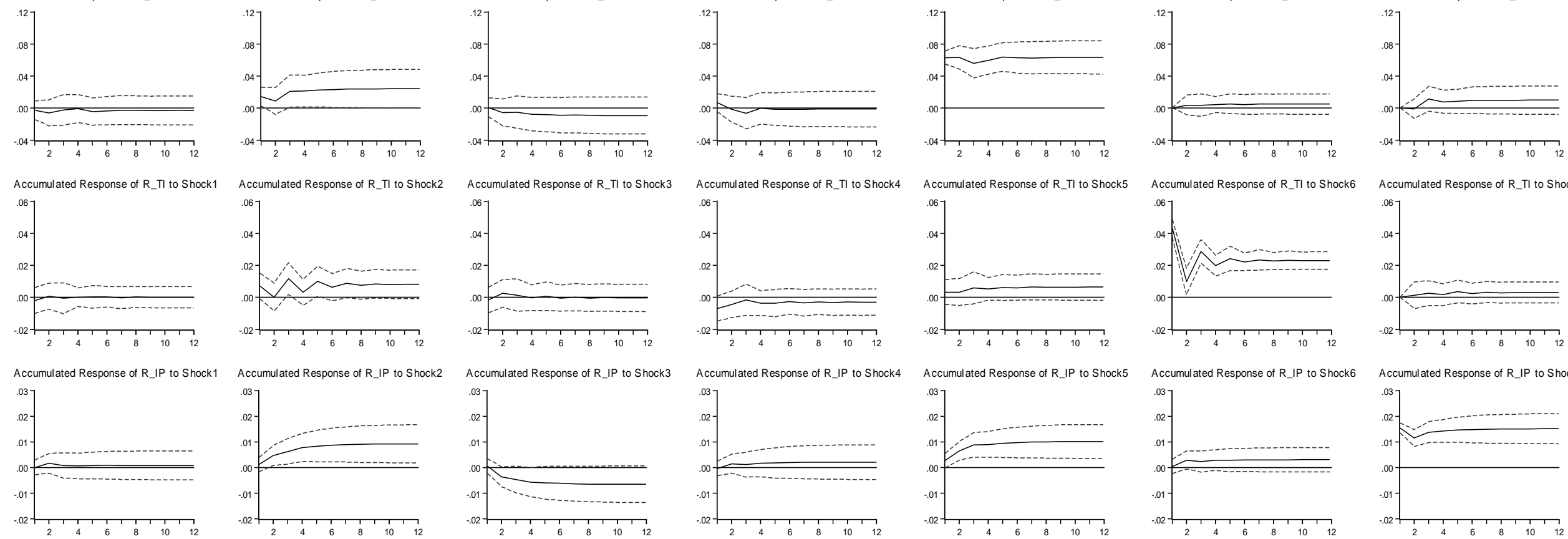
Accumulated Response to Structural One S.D. Innovations \pm 2 S.E.
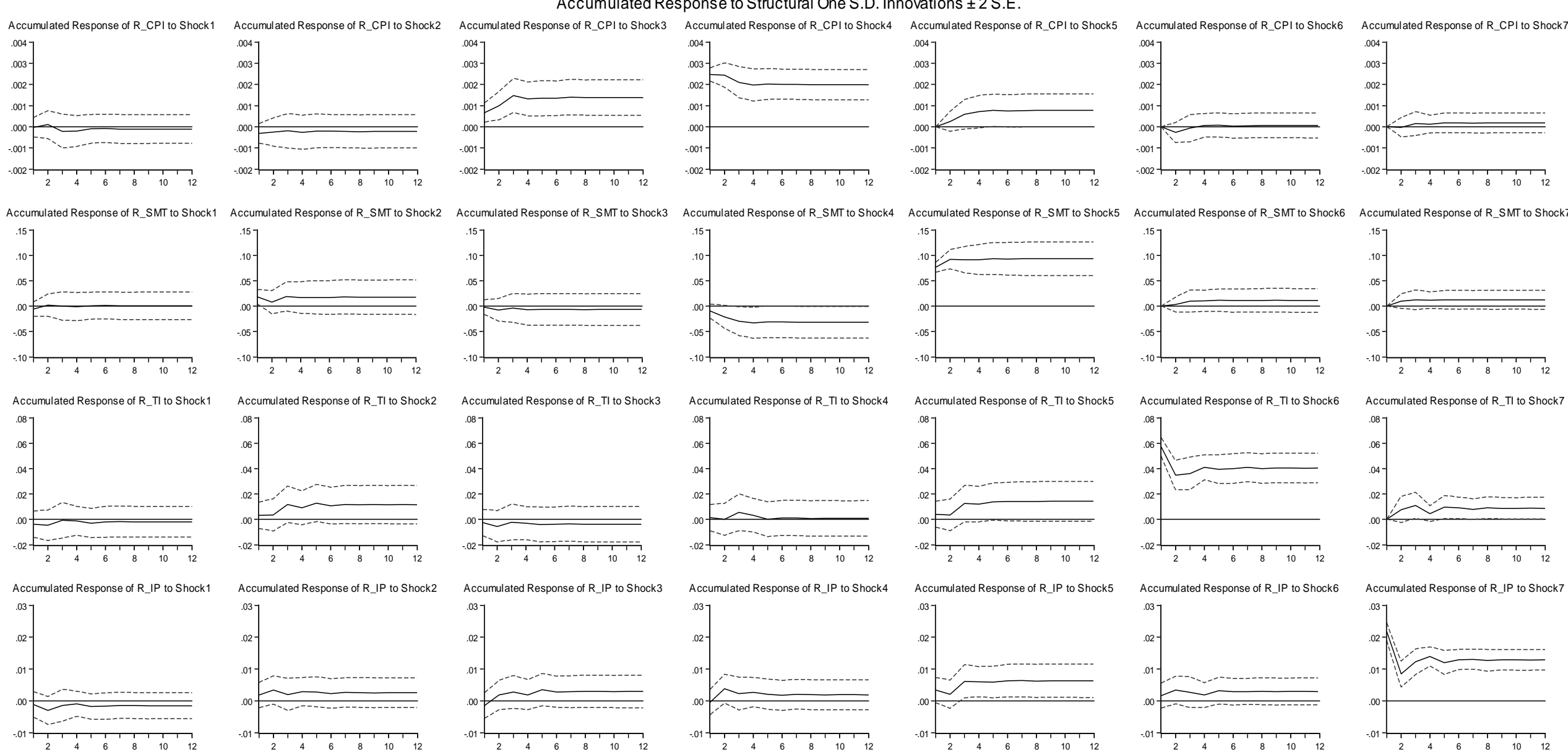

Accumulated Response of $R$ TI to Shock

Accumulated Response of R_Tl to Shock7
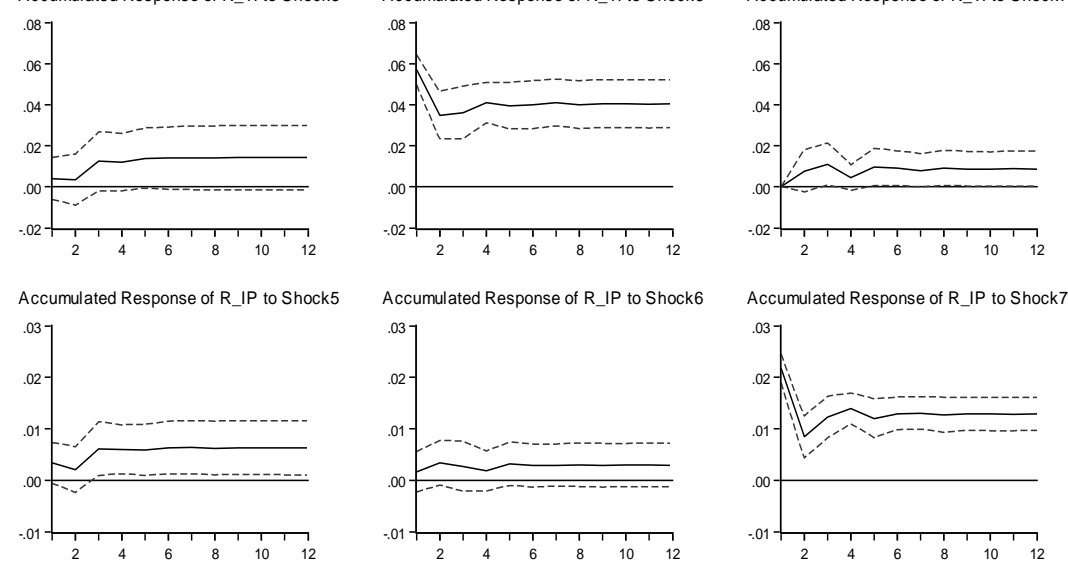
Accumulated Response to Structural One S.D. Innovations \pm 2 S.E.

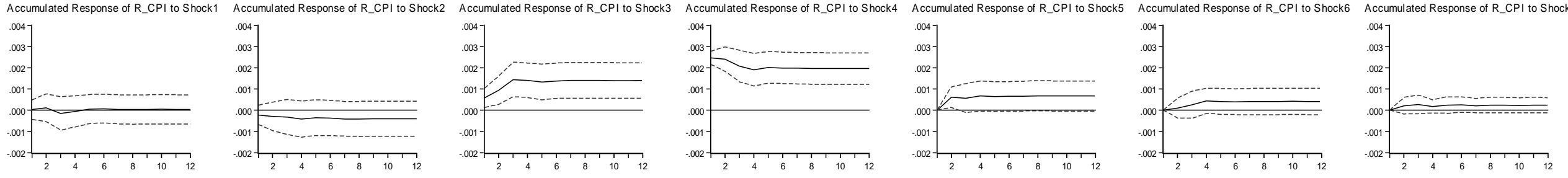

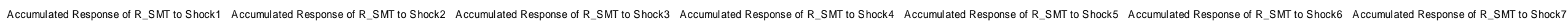
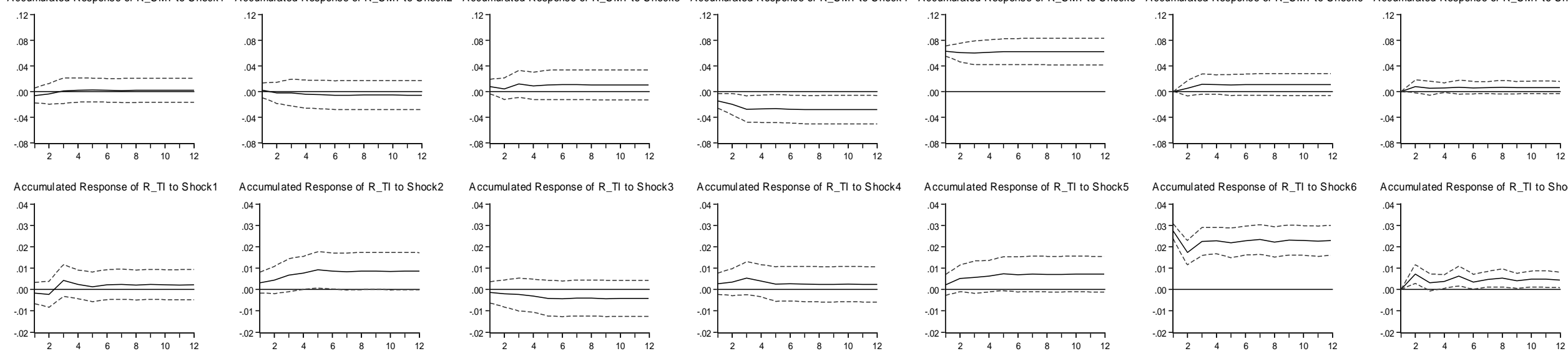

Accumulated Response of R_Tl to Shock7
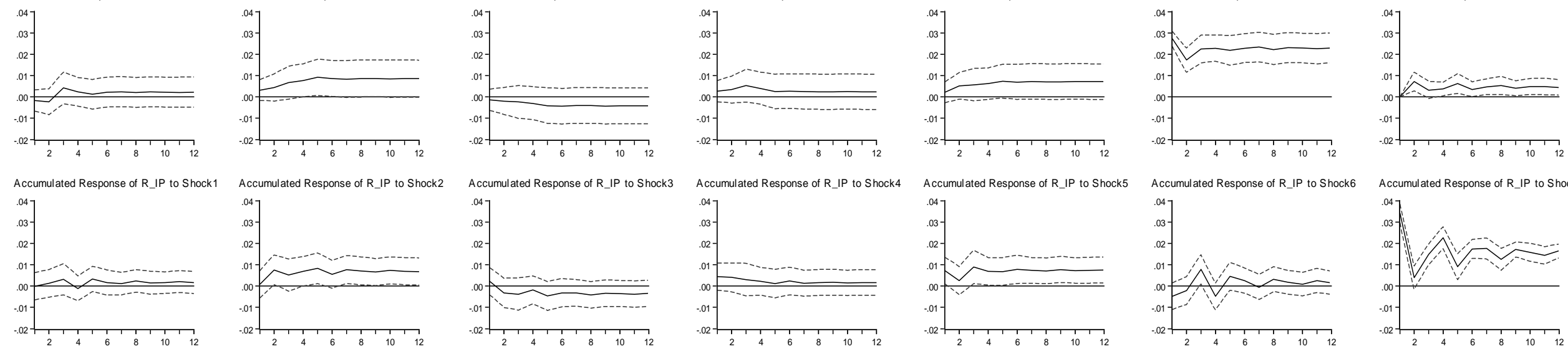
Tables:

Table 1: Comparison of the empirical results for tourism and economic growth

\begin{tabular}{|c|c|c|c|c|}
\hline Authors (year) & Empirical Method Employed & Period of study & Country / Group & Hypothesis Supported \\
\hline Fayissa et al (2011) & Dynamic Panel Data Analysis & $1990-2005$ & $\begin{array}{l}18 \text { Heterogenous } \\
\text { Latin America Countries }\end{array}$ & TLEG \\
\hline Kasimati (2011) & VECM & $1960-2010$ & Greece & Bidirectional Relationship \\
\hline Schubert (2011) & VECM and Granger Causality test & $1970-2008$ & Antigua, Barbuda & TLEG \\
\hline Brida et al (2010) & Cointegration Analysis & $1987-2006$ & Uruguay & TLEG \\
\hline $\begin{array}{l}\text { Cortès-Jimenez } \\
\text { et al (2009) }\end{array}$ & $\begin{array}{l}\text { Cointegration Analysis \& } \\
\text { GrangerCausality Tests }\end{array}$ & $1954-2000$ & Italy & Bidirectional Relationship \\
\hline $\begin{array}{l}\text { Cortès-Jimenez } \\
\text { et al (2009) }\end{array}$ & $\begin{array}{l}\text { Cointegration Analysis \& } \\
\text { GrangerCausality Tests }\end{array}$ & $1964-2000$ & Spain & Bidirectional Relationship \\
\hline Katricioglu (2009) & Johansen Cointegration Analysis & $1960-2006$ & Turkey & NO Causality \\
\hline Zortuk (2009) & VECM & $1992-2008$ & Turkey & TLEG \\
\hline Carrera et al (2008) & Johansen Cointegration Analysis & $1980-2007$ & Mexico & TLEG \\
\hline Lee \& Chang (2008) & Panel Cointegration & $1990-2002$ & OECD Countries & TLEG \\
\hline Lee \& Chang (2008) & Panel Cointegration & $1990-2002$ & $\begin{array}{l}\text { Non- } \\
\text { OECD Countries }\end{array}$ & Bidirectional Relationship \\
\hline Proenca \& Soukiazis (2008) & Panel Data Analysis & $1993-2001$ & Portugal & TLEG \\
\hline Kim et al. (2006) & Granger Causality Test & $1971-2003$ & Taiwan & TLEG \\
\hline Gunduz \& Hatemi-J (2005) & VAR & $1963-2002$ & Turkey & TLEG \\
\hline Oh (2005) & Granger Causality Test & $1975-2001$ & Korea & EDTG \\
\hline Dritsakis (2004) & VECM & $1960-2000$ & Greece & Bidirectional Relationship \\
\hline Durbarry (2004) & VECM & 1952-1999 & Mauritius & Bidirectional Relationship \\
\hline $\begin{array}{l}\text { Eugenio-Martin \& } \\
\text { Morales (2004) }\end{array}$ & Panel GLS & $1980-1997$ & $\begin{array}{l}\text { Low and Medium-income } \\
\text { Latin America } \\
\text { Countries }\end{array}$ & TLEG \\
\hline $\begin{array}{l}\text { Eugenio-Martin \& } \\
\text { Morales (2004) }\end{array}$ & Panel GLS & 1980-1997 & $\begin{array}{l}\text { High-income } \\
\text { Latin America } \\
\text { Countries }\end{array}$ & NO Causality \\
\hline Narayan (2004) & VECM & $1970-2000$ & Fiji & EDTG \\
\hline
\end{tabular}




\begin{tabular}{|c|c|c|c|c|c|c|c|c|c|c|c|c|}
\hline & 2000 & 2001 & 2002 & 2003 & 2004 & 2005 & 2006 & 2007 & 2008 & 2009 & 2010 & Average \\
\hline \multicolumn{13}{|l|}{ Italy } \\
\hline Inbound Tourist Arrivals: Total ('000) & 62,702 & 60,960 & 63,561 & 63,026 & 58,480 & 59,230 & 66,353 & 70,271 & 70,719 & 71,692 & 73,225 & 65,474 \\
\hline Inbound Tourist Arrivals: Overnight Visitors ('000) & 41,181 & 39,563 & 39,799 & 39,604 & 37,071 & 36,513 & 41,058 & 43,654 & 42,734 & 43,239 & 43,626 & 40,731 \\
\hline Inbound tourism expenditure over GDP (\%) & 1.6 & 1.5 & 1.5 & 1.4 & 1.5 & 1.5 & 1.7 & 1.7 & 1.7 & 1.5 & 1.5 & 1.6 \\
\hline Inbound tourism expenditure over exports of services (\%) & 50.8 & 46.7 & 46.6 & 45.4 & 44.8 & 43 & 42.1 & 41.1 & 41.6 & 43.7 & 40.9 & 44.2 \\
\hline \multicolumn{13}{|l|}{ France } \\
\hline Inbound Tourist Arrivals: Total ('000) &.. & .. & .. &.. & 190,282 & 185,829 & 193,882 & 193,319 & 193,571 & 192,369 & 189,881 & 191,305 \\
\hline Inbound Tourist Arrivals: Overnight Visitors ('000) & 77,190 & 75,202 & 77,012 & 75,048 & 74,433 & 74,988 & 77,916 & 80,853 & 79,218 & 76,764 & 77,148 & 76,888 \\
\hline Inbound tourism expenditure over GDP (\%) & 2.5 & 2.4 & 2.4 & 2.2 & 2.2 & 2.1 & 2.1 & 2.1 & 2 & 1.9 & 1.8 & 2.1 \\
\hline Inbound tourism expenditure over exports of services (\%) & 39.7 & 39.1 & 39.5 & 38.8 & 39.2 & 36 & 36.1 & 36.2 & 34.4 & 34.3 & 31.7 & 36.8 \\
\hline \multicolumn{13}{|l|}{ Spain } \\
\hline Inbound Tourist Arrivals: Total ('000) & 74,580 & 75,564 & 79,313 & 82,326 & 85,981 & 92,563 & 96,152 & 98,907 & 97,670 & 91,899 & 93,729 & 88,062 \\
\hline Inbound Tourist Arrivals: Overnight Visitors ('000) & 46,403 & 48,565 & 50,331 & 50,854 & 52,430 & 55,914 & 58,004 & 58,666 & 57,192 & 52,178 & 52,677 & 53,019 \\
\hline Inbound tourism expenditure over GDP (\%) & 5.6 & 5.6 & 5.2 & 5 & 4.8 & 4.7 & 4.7 & 4.5 & 4.4 & 4.1 & 4.2 & 4.8 \\
\hline Inbound tourism expenditure over exports of services (\%) & 62.3 & 60.8 & 58.9 & 59 & 58.1 & 56.1 & 53.9 & 50.7 & 49 & 48.4 & 47.6 & 55 \\
\hline \multicolumn{13}{|l|}{ Greece } \\
\hline Inbound Tourist Arrivals: Total ('000) & 13,567 & 14,678 & 14,918 & 14,785 & 14,268 & 15,938 & 17,284 & .. & .. & .. & .. & 15,063 \\
\hline Inbound Tourist Arrivals: Overnight Visitors ('000) & 13,096 & 14,057 & 14,180 & 13,969 & 13,313 & 14,765 & 16,039 & 16,165 & 15,939 & 14,915 & 15,007 & 14,677 \\
\hline Inbound tourism expenditure over GDP (\%) & 7.3 & 7 & 6.8 & 5.6 & 5.6 & 5.6 & 5.5 & 5 & 5.1 & 4.5 & 4.1 & 5.6 \\
\hline Inbound tourism expenditure over exports of services (\%) & 48.1 & 47.4 & 49.7 & 44.6 & 38.7 & 39.7 & 40.5 & 36.4 & 34.8 & 39.2 & 33.6 & 41.2 \\
\hline
\end{tabular}

Source: Adapted from World Tourism Organization 
Table 3: Mode of transport - Average for period 2000-2010

\begin{tabular}{lcccc}
\hline Mode of Transport & France & Italy & Spain & Greece \\
\hline Air (\%) & 22.8 & 25.9 & 74.2 & 71.5 \\
Land (\%) & 68.0 & 70.4 & 23.2 & 19.2 \\
\hline
\end{tabular}

Source: Adapted from World Tourism Organization

Table 4: SVAR contemporaneous coefficients

\begin{tabular}{|c|c|c|c|c|c|c|c|c|}
\hline Coefficient & Italy & & France & & Spain & & Greece & \\
\hline$\alpha_{11}$ & 0.0082 & $* * *$ & 0.0083 & $* * *$ & 0.0081 & $* * *$ & 0.0083 & $* * *$ \\
\hline$\alpha_{21}$ & 1.5260 & & 2.7486 & $*$ & 2.5202 & & 3.5445 & \\
\hline$\alpha_{22}$ & 1.5443 & $* * *$ & 1.536 & $* * *$ & 1.5254 & $* * *$ & 1.4533 & $* * *$ \\
\hline$\alpha_{31}$ & 0.0086 & & -0.3252 & & -0.0227 & & -0.1702 & \\
\hline$\alpha_{32}$ & 0.0292 & $* * *$ & 0.0257 & $* * *$ & 0.0274 & $* * *$ & 0.0224 & $* * *$ \\
\hline$\alpha_{33}$ & 0.1129 & $* * *$ & 0.1134 & $* * *$ & 0.1147 & $* * *$ & 0.1132 & $* * *$ \\
\hline$\alpha_{41}$ & 0.0205 & & 0.0020 & & 0.0003 & & 0.0054 & \\
\hline$\alpha_{42}$ & 0.0001 & & 0.0002 & & 0.0000 & & 0.0001 & \\
\hline$\alpha_{43}$ & 0.0038 & $* *$ & 0.0071 & $* * *$ & 0.0054 & $* * *$ & 0.0059 & $* * *$ \\
\hline$\alpha_{44}$ & 0.0020 & $* * *$ & 0.0018 & $* * *$ & 0.0025 & $* * *$ & 0.0025 & $* * *$ \\
\hline$\alpha_{51}$ & 0.2191 & & 0.4364 & & 1.4185 & & 0.6668 & \\
\hline$\alpha_{52}$ & -0.0039 & & 0.0038 & & -0.0086 & & -0.0018 & \\
\hline$\alpha_{53}$ & -0.0999 & $*$ & -0.0157 & $*$ & -0.0627 & $*$ & -0.1890 & $* * *$ \\
\hline$\alpha_{54}$ & -3.8297 & & 1.1513 & & 3.8086 & & 3.9445 & \\
\hline$\alpha_{55}$ & 0.0620 & $* * *$ & 0.0907 & $* * *$ & 0.0976 & $* * *$ & 0.0753 & $* * *$ \\
\hline$\alpha_{56}$ & 0.0996 & & 0.0305 & & 0.1874 & & 0.0777 & \\
\hline$\alpha_{57}$ & 0.6741 & $*$ & 0.7543 & & 0.4546 & $*$ & 0.5034 & \\
\hline$\alpha_{61}$ & 0.3312 & & -0.4144 & & 0.1976 & & 0.4584 & \\
\hline$\alpha_{62}$ & -0.0005 & & 0.0001 & & 0.0001 & & 0.0011 & \\
\hline$\alpha_{63}$ & -0.0762 & $* *$ & -0.0142 & & -0.0246 & & -0.0255 & \\
\hline$\alpha_{64}$ & -3.5612 & $*$ & -1.5916 & & -1.1375 & & -0.5888 & \\
\hline$a_{66}$ & 0.0434 & $* * *$ & 0.0493 & $* * *$ & 0.0273 & $* * *$ & 0.0573 & $* * *$ \\
\hline$a_{71}$ & -0.0020 & & -0.0041 & & 0.1046 & & 0.1197 & \\
\hline$\alpha_{72}$ & -0.0006 & & 0.0005 & & -0.0013 & & -0.0010 & \\
\hline$\alpha_{73}$ & -0.0086 & & -0.0156 & & -0.0065 & & 0.0139 & \\
\hline$\alpha_{76}$ & 0.0138 & & 0.0066 & & 0.1253 & & 0.0329 & \\
\hline$\alpha_{77}$ & 0.0156 & $* * *$ & 0.0122 & $* * *$ & 0.0349 & $* * *$ & 0.0220 & $* * *$ \\
\hline $\begin{array}{l}{ }^{* * *} \text { denotes sig } \\
\text { ** denotes sign } \\
{ }^{*} \text { denotes signifi }\end{array}$ & $\begin{array}{l}\text { at } 1 \% \text { level } \\
5 \% \text { level. } \\
10 \% \text { level. }\end{array}$ & & & & & & & \\
\hline
\end{tabular}

